\title{
POPPER E A ELIMINAÇÃO DO PROBLEMA DA INDUÇÃO
}

Valdirlen do Nascimento Loyolla ${ }^{1}$

\begin{abstract}
RESUMO
O presente artigo destina-se a apresentar as críticas de Popper à solução humeana e a versão neopositivista para o problema da indução. Para tanto, o seu principal objetivo é desenvolver o princípio do racionalismo crítico contra qualquer princípio indutivista na ciência. Nesse nível, ele enfatiza a inexistência do princípio de indução e, por conseguinte, de uma lógica indutiva nos contextos de descoberta e justificação de hipóteses científicas. E mais, reafirmando a sua posição frente ao problema da indução, indica-nos que o procedimento adotado para descobrir hipóteses não pode ser caracterizado racionalmente e que o procedimento que se adota para a justificação de hipóteses pode ser analisado sem o uso da lógica indutiva.
\end{abstract}

PALAVRAS-CHAVE: Indução. Método indutivo. Justificação de hipóteses.

\begin{abstract}
This article aims to present Popper's criticisms of the Humean solution and the neopositivist version of the problem of induction. To this end, its main objective is to develop the principle of critical rationalism against any inductive principle in science. At this level, he emphasizes the inexistence of the principle of induction and, consequently, of an inductive logic in the contexts of discovery and justification of scientific hypotheses. Moreover, reaffirming its position on the problem of induction, it indicates to us that the procedure adopted to discover hypotheses can not be rationally characterized and that the procedure adopted for the justification of hypotheses can be analyzed without the use of inductive logic.
\end{abstract}

KEYWORDS: Induction. Inductive method. Justification of hypotheses.

\section{INTRODUÇÃO}

O presente artigo tem como objeto e problema de pesquisa análise do alcance das críticas de Karl Popper à solução humeana e a versão neopositivista para o problema da indução, instauradas a partir do seu princípio do racionalismo crítico desenvolvido contra qualquer princípio indutivista na ciência. Nesse sentido, a nossa metodologia de pesquisa, de cunho fundamentalmente bibliográfico, consistiu em contrastar as abordagens popperianas acerca do "problema da indução" expostas no corpus de suas obras: (1975a) A

${ }^{1} \mathrm{O}$ autor, Valdirlen do Nascimento Loyolla, é Graduado em Filosofia pela Universidade Federal de Ouro Preto (UFOP), Especialista em Filosofia Contemporânea pela FCV-Paraná, Mestre e Doutor em Lógica e Filosofia da Ciência pela Universidade Federal de Minas Gerais (UFMG). Atualmente é professor do Departamento de Filosofia da Universidade Estadual de Montes Claros-MG (UNIMONTES). Artigo recebido em 03/10/2019 e aceito em 16/11/2019.

Perspectivas - Revista do Programa de Pós-Graduação em Filosofia da UFT - v. 2 n. 2 (2017) 
lógica da pesquisa científica; (1975b) Conhecimento objetivo: uma abordagem evolucionária; (1982) Conjecturas e refutações; (1987) O realismo e o objetivo da ciência ("Pós-escrito" à Lógica da pesquisa científica).

De acordo com Karl Popper uma teoria da indução é supérflua para o conhecimento científico, não tendo nenhum papel a desempenhar em uma lógica da ciência. A questão de saber como uma ideia nova ocorre ao homem e como deve ser justificada pode ser avaliada, segundo ele, a partir da distinção entre a psicologia do conhecimento e a lógica do conhecimento. A crença na Lógica Indutiva deve-se, em grande parte, a uma confusão entre problemas psicológicos e problemas epistemológicos.

\begin{abstract}
$\mathrm{O}$ estágio inicial, o ato de conceber ou inventar uma teoria, parece-me não reclamar análise lógica, nem ser dela suscetível. A questão de saber como uma idéia nova ocorre ao homem - trate-se de um tema musical, de um conflito dramático ou de uma teoria científica - pode revestir-se de grande interesse para a psicologia empírica, mas não interessa à análise lógica do conhecimento científico. Esta última diz respeito não a questões de fato (o quid facti?de Kant), mas apenas a questões de justificação ou validade (o quid juris? de Kant). (POPPER, 1975a, p. 31)
\end{abstract}

Dentre os muitos aspectos do pensamento popperiano, há que ressaltar o caráter singular e original de suas preocupações quanto às distinções de problemas psicológicos e lógicos, por um lado, e epistemológicos e metodológicos, por outro. Diferentemente da concepção neopositivista, a popperiana estabelece que o problema central da Filosofia é o da análise crítica do apelo à autoridade da experiência. Nesse sentido, uma das tarefas mais importantes da crítica filosófica consiste em tornar conscientes os mais variados sistemas de crenças. Nesse âmbito, o problema de Popper será, então, resolver o problema da indução, criticando, desde as suas bases, as soluções humeana e neopositivista a partir da instauração do princípio do racionalismo crítico e, em seguida, estabelecer os meios para propor o método empírico (critério da falsificabilidade) como substitutivo do método empirista (critério de significação) para resolver o problema da demarcação entre ciência e metafísica.

\title{
1 CRÍTICAS DE POPPER À INDUÇÃO: O PRINCÍPIO DO RACIONALISMO CRÍTICO
}

O problema filosófico tradicional da indução pode ser formulado através da questão: que tipo de justificação podemos invocar para nossas inferências indutivas em geral? Em outras palavras: como pode a indução ser justificada? Nesse sentido, Hume assevera que a 
inferência indutiva não pode ser racionalmente justificada. Por outro lado, os indutivistas (neopositivistas) supõem que as inferências indutivas podem ser justificadas racionalmente, coisa que Popper nega veementemente. Para ele, "não há indução", seja ela feita pelo hábito ou pela razão. Todavia, baseando-se na colocação inicial de Hume, Popper discerne dois problemas: um lógico - ao qual Hume dará uma resposta terminantemente negativa - e outro psicológico ${ }^{2}$.

O problema lógico da indução em Hume consiste em saber se estamos racionalmente justificados a fazer inferências a partir de vários casos particulares observados para conclusões relativas aos casos não observados, ou melhor, se nós estamos justificados racionalmente a argumentar a partir de casos repetidos, dos quais tivemos experiência, para os casos dos quais não tivemos nenhuma experiência. A resposta inflexível de Hume é: "não, nós não estamos racionalmente justificados", porém, "se o número de repetições for grande o suficiente, pode ser”. Neste último caso, não se pede a justificação de qualquer crença, mas da crença provável; em outras palavras, os casos dos quais tivemos experiências não nos permitem argumentar ou discutir sobre a probabilidade dos casos dos quais não tivemos nenhuma experiência, qualquer que seja a certeza que tenhamos de tais exemplos. Na ótica humeana, mesmo considerando a inferência como provável, a resposta negativa se mantém. Esse último aspecto negativo da resposta de Hume busca vedar qualquer possibilidade de instauração da indução em termos de probabilidade ${ }^{3}$.

O problema psicológico da indução, dada a negatividade da sua justificação lógica, consistirá em saber porque os cientistas são levados à crença de que os casos não observados (as premissas ausentes) poderão conformar-se aos que foram observados. A resposta de Hume para o problema psicológico da indução é: "por causa do costume ou hábito"; ou, em outras palavras, por causa do irracional e irresistível poder da lei de associação, um mecanismo condicionador sem o qual, Hume diz, "nós certamente não poderíamos sobreviver".

Se por um lado, Popper concorda com Hume quanto anão-validade racional da indução, por outro, desconsidera suas assertivas quanto aos pressupostos não-racionais das leis científicas. Segundo ele, o anti-racionalismode Hume deriva da interação desses dois problemas conjugada à observação de que todo raciocínio sobre questões de fato é indutivo. Para evitar o anti-racionalismo de Hume, Popper terá que reformular o problema lógico da

${ }^{2}$ Cf. POPPER, 1975b, p. 15.

${ }^{3}$ Cf. HUME, 1996, p. 72-73; 2001, p. 168.

Perspectivas - Revista do Programa de Pós-Graduação em Filosofia da UFT - v. 2 n. 2 (2017) 
indução. Vejamos o esquema traçado por ele para a implementação de sua abordagemcrítica às conclusões humeanas ${ }^{4}$ :

i) manutenção da condição primeira de Hume: há inúmeras regularidades aparentes na natureza nas quais toda a gente, na prática, confia, e muitas leis universais da natureza aceitas pelos cientistas as quais são de grande importância teórica para a ciência;

ii) reformulação do segundo ponto: não pode haver um raciocínio válido que parta de proposições singulares de observação para inferir leis universais da natureza, logo, para inferir teorias científicas; este é o princípio da invalidade da indução;

iii) reformulação do terceiro ponto: a adoção e a rejeição de teorias científicas devem depender dos resultados da observação e da experimentação, e, portanto, de enunciados singulares (enunciados básicos) de observação; este é o princípio do empirismo.

Conclusões de Popper acerca das considerações acima estipuladas:

a) O choque de $i$, por um lado, com $i i$ e iii, por outro, constitui o problema de Hume: o problema lógico da indução;

b) Supondo, agora, o ponto $i$ verdadeiro, vemos que o problema lógico da indução consiste, então, no choque aparente entre o princípio da invalidade da indução e o princípio do empirismo;

c) O empirismo parece implicar que, sem a indução, não podemos ter conhecimento científico;

d) Entretanto, a aceitação dos pontos ii e iii, diferentemente de Hume, não leva ao antiracionalismo (os pontos $i i$ e iii são não só compatíveis como também consistentes em relação ao seguinte princípio: a adoção e a rejeição de teorias científicas devem depender do raciocínio crítico, combinado com os resultados da observação e da experimentação, tal como exigido pelo princípio do empirismo; este é o princípio doracionalismo crítico);

e) Para vermos que a "condição primeira de Hume" e o princípio do racionalismo crítico são consistentes, teremos apenas que perceber que a adoção de teorias científicas só se pode dar a título de ensaio; que essas teorias são sempre, e sempre serão, suposições, conjecturas ou hipóteses ${ }^{5}$.

De acordo com Popper, o princípio do racionalismo crítico não só resolve o problema da indução de um ponto de vista lógico como também veda qualquer tentativa de justificação pragmática da mesma. Esta tentativa pode ser reconhecida como o problema da indução em

${ }^{4}$ Cf. POPPER, 1987, p. 63-65.

${ }^{5}$ Cf. POPPER, 1987,p. 64.

Perspectivas - Revista do Programa de Pós-Graduação em Filosofia da UFT - v. 2 n. 2 (2017) 
termos psicológicos, ou melhor, como o problema de procurar dar uma explicação causal a um fato psicológico - o fato de que acreditamos em leis, em assertivas que afirmam a regularidade de certos eventos na natureza, ou em certos tipos de eventos constantemente associados - afirmando que este fato é devido ao hábito ou costume ${ }^{6}$.

Para Popper, a chave da solução do problema da indução consiste no reconhecimento de que as nossas teorias, mesmo as mais importantes, nunca deixam de sersuposições ou conjecturas. Se, de fato, são verdadeiras, jamais poderemos saber, nem a partir da experiência, nem de qualquer outra fonte ${ }^{7}$. Somente através do reconhecimento de que a ciência consiste em conjecturas é que podemos resolver o problema da indução (seja o de Hume ou sua reformulação neopositivista) sem ter de pressupor, para isso, quaisquer limites ao empirismo, isto é, sem adotar um princípio de indução dotando-o de validade a priori ${ }^{8}$. Acerca desse problema, Popper argumenta criticamente:

\begin{abstract}
Acreditando que o nosso conhecimento empírico fosse obtido por indução, e estando profundamente impressionado pela força crítica de Hume, Russell sugeriu que tínhamos de aceitar um princípio de indução, o qual, por sua vez, não podia basear-se na indução: um princípio cuja adoção assinalava os limites do empirismo. (POPPER, 1987, p. 46)
\end{abstract}

A observação crítica de Popper interpreta o problema da justificação do princípio de indução como tentativa de meta-justificação do mesmo. Isto é, para justificar um princípio de indução de ordem inferior, necessitaríamos de um princípio de indução de ordem superior ao primeiro (diríamos, um meta-princípio, e assim por diante). Nessa sucessão, deparamos com um regressum ad infinitum. Para Popper, o princípio de indução deve ser um enunciado universal. Assim, se tentarmos considerar sua verdade como decorrente da experiência surgirão, de novo, os mesmos problemas que levaram à sua formulação. E, para justificá-lo, teremos que recorrer às inferências indutivas e, para justificá-las, teremos de admitir um princípio de indução de ordem mais elevada e sucessivamente, fracassando na tentativa de fundamentar o princípio de indução na experiência ${ }^{9}$. Deste modo, corroborando as observações de Hume quanto ao caráter lógico de tal princípio, Popper nos alerta:

Ora, o princípio de indução não pode ser uma verdade puramente lógica, tal como uma tautologia ou um enunciado analítico. De fato, se existisse algo assim como um princípio puramente lógico de indução, não haveria problema de indução, pois,

${ }^{6}$ Cf. POPPER,1982, p. 73.

${ }^{7}$ Cf. POPPER, 1987, p. 64.

${ }^{8}$ Cf. POPPER, 1987, p. 47

${ }^{9}$ Cf. POPPER,1975a, p. 29.

Perspectivas - Revista do Programa de Pós-Graduação em Filosofia da UFT - v. 2 n. 2 (2017) 
em tal caso, todas as inferências indutivas teriam de ser encaradas como transformações puramente lógicas ou tautológicas, exatamente como as inferências no campo da Lógica Dedutiva. Assim sendo, o princípio de indução há de constituir-se num enunciado sintético, ou seja, um enunciado cuja negação não se mostre contraditória, mas logicamente possível. Dessa maneira, surge a questão de saber por que tal princípio deveria merecer aceitação e como poderíamos justificar-lhe a aceitação em termos racionais. (POPPER,1975a, p. 28)

O problema epistemológico de Hume, de acordo com Popper, pode ser identificado como o problema de dar razões justificativas positivas e que pode perfeitamente ser substituído pelo problema de explicar dando razões críticas, ou melhor, pelo problema de discutir criticamente hipóteses. Tal solução não é, sob nenhuma circunstância, justificacionista, pois mesmo que ofereça uma solução negativa, isto é, não-justificacionista (ou não-fundacionista), permite que o problema tenha uma solução que não é cética, nem irracionalista. A solução proposta por Popper é compatível com a ideia de que o nosso conhecimento científico é conjectural, podendo crescer através do uso da razão e do argumento crítico ${ }^{10}$.

Contudo, para programar as suas razões contra-indutivistas, tanto no plano metodológico quanto epistemológico e levar adiante o seu projeto de eliminação da indução do rol da ciência empírica, Popper terá que combater criticamente - de forma radical e mais severamente possível - a abordagem neopositivista da justificação racional da indução.

A análise popperiana do chamado problema da base empírica ${ }^{11}$ busca caracterizar de forma mais precisa a função dos enunciados observacionais singulares (enunciados básicos) em sua teoria da ciência empírica, uma vez que, para ele, os enunciados básicos só serão empíricos se falseáveis. Segundo Popper, a teoria da base empírica apresentada pelo neopositivismo estabelece uma forte concepção psicologista, pois considera que os enunciados básicos podem ser justificados por nossa experiência perceptual. De acordo com essa doutrina os enunciados das ciências empíricas seriam redutíveis a percepções sensoriais, ao passo que os da matemática e da lógica se alicerçariam no pensamento. O problema da

\footnotetext{
${ }^{10}$ Cf. POPPER, 1987, p. 54.

${ }^{11}$ Entende-se por base empírica o conjunto dos objetos que, potencialmente, podem ser conhecidos diretamente. Claro que nem todo objeto do qual se ocupam as ciências empíricas se encontra nessa condição; por exemplo, os átomos, as moléculas, os genes etc., não possuem essa qualidade de "observável diretamente", pois, para ascendermos ao conhecimento dessas entidades, torna-se necessário proceder indiretamente, através de dispositivos ou estratégias mediatizadoras, e justificar nossa crença em suas existências, em nosso modo de conhecê-las. Essa distinção entre observável (base empírica) e inobservável (zona teórica) traz consequências tanto metodológicas quanto epistemológicas para a compreensão do conhecimento científico (Cf. KLIMOVSKY, 1995, p. 31).
}

Perspectivas - Revista do Programa de Pós-Graduação em Filosofia da UFT - v. 2 n. 2 (2017) 
base dos enunciados da experiência é, segundo o pensamento popperiano, antes um fruto da confusão entre psicologia e lógica, do que um problema epistemológico ${ }^{12}$.

A concepção neopositivista afirma que, se não cabe aceitar dogmaticamente os enunciados da ciência, deve-se ter como justificá-los racionalmente. A exigência de justificação pautada em argumentos que se baseiem em razões positivas leva obrigatoriamente à concepção de que enunciados só podem ser justificados por enunciados. Nesse âmbito, a exigência de que todos os enunciados devam ser logicamente justificados tende a conduzir a uma regressão infinita. Diante desse problema, procurando evitar não só o dogmatismo como a regressão infinita, o recurso utilizado foi o desenvolvimento da tese de que enunciados podem encontrar justificação não só em enunciados, mas também na experiência perceptual, ou seja, em alguma forma de psicologismo que alimenta a ideia segundo a qual através da experiência imediata encontramos meios para justificar e expressar o conhecimento no simbolismo de alguma linguagem. Assim, baseando-se no imediato sentimento de convicção que a experiência perceptual nos transmite (acerca de nossas experiências), busca-se distinguir o enunciado verdadeiro do enunciado falso. Para os neopositivistas, o enunciado verdadeiro seria aquele cujos termos estão em concordância com a experiência; caso contrário, seria falso ${ }^{13}$.

A abordagem crítica de Popper aponta para o fato de que, além de apoiar-se no problema da indução, a epistemologia do empirismo lógico reclama para si o problema dos universais. A perspectiva crítica popperiana afirma que toda descrição ou enunciado usa termos ou nomes universais. Um enunciado básico não admite verificação por qualquer experiência observacional simplesmente por que os nomes (universais) que nele ocorrem não podem ser correlacionados com qualquer experiência sensorial: os termos universais não admitem redução a classes de experiências, sejam elas imediatas ou não ${ }^{14}$.

As objeções neopositivistas contra a conceituação popperiana relativa à base empírica podem ser formuladas através das seguintes questões:

a) "quais são os critérios para a aceitação dos enunciados básicos como verdadeiros ou falsos?"; e,

b) "como aceitar a significação dos termos (nomes) que fazem parte dos enunciados básicos?".

\footnotetext{
${ }^{12}$ Cf. POPPER,1975a, p. 99.

${ }^{13}$ Cf. POPPER, 1975a, p. 100.

${ }^{14}$ Cf. POPPER, 1975a, p. 101.

Perspectivas - Revista do Programa de Pós-Graduação em Filosofia da UFT - v. 2 n. 2 (2017)
} 
No que diz respeito à primeira questão, a resposta de Popper é conclusiva:

As experiências podem motivar uma decisão e, conseqüentemente, a aceitação ou rejeição de um enunciado, mas um enunciado básico não pode ver-se justificado por elas (...). (POPPER, 1975a, p. 113)

O diagnóstico de Popper a respeito da segunda questão buscará criticar o ideal neopositivista de ciência como capaz de construir conceitos a partir de experiências sensoriais. Segundo Popper, isso se deve ao fato de esse ideal fundar-se na crença da existência da indução ${ }^{15}$.

Para Popper, no nível de um enunciado observacional está suposta toda uma série de hipóteses. E, como são hipóteses, são falíveis, comprometendo toda a segurança da base empírica ${ }^{16}$.

De acordo com o método da abordagem crítica de Popper, a epistemologia indaga como submeter enunciados científicos a testes, considerando suas consequências dedutivas. Grosso modo, a maioria dos neopositivistas deve reconhecer que qualquer tentativa de alicerçar os enunciados lógicos em sentenças perceptuais traduz uma forte inclinação ao psicologismo $^{17}$.

A diferença fundamental entre a perspectiva de Popper e a dos neopositivistas pautase no fato de que só através da constatação do caráter conjectural do conhecimento científico é que podemos resolver o problema da indução sem ter de pressupor um princípio de indução nem quaisquer limites ao empirismo. A esse respeito, diz Popper:

\footnotetext{
Se supusermos que aquilo a que se chama "conhecimento científico" é constituído unicamente por conjecturas, então essa suposição será suficiente para resolver o problema da indução - chamado, por Kant, "o problema de Hume" - sem sacrificar o empirismo, isto é, sem adotar um princípio da indução, dotando-o de validade $a$ priori. Pois as suposições não são "induzidas a partir de observações" (ainda que possam, é claro, ser-nos sugeridas por observações). Este fato permite-nos aceitar sem reservas (e sem os limites que Russell põe ao empirismo) a crítica lógica de Hume à indução, e desistir, assim, da busca de uma lógica indutiva, da certeza, e até da probabilidade, mas prosseguindo, entretanto, a nossa busca científica da verdade. (POPPER, 1987, p. 47)
}

Segundo Popper, a aceitação do empirismo - que não impusesse a si mesmo aqueles limites kantianos que Russell aceitava - não implica de forma alguma na aceitação da indução. Ao sugerir que a ciência seria impossível se prevalecessem às ideias de Hume,

\footnotetext{
${ }^{15}$ Cf. POPPER, 1975a, p. 100.

${ }^{16}$ Cf. POPPER, 1975a, p. 120.

${ }^{17} \mathrm{Cf}$. POPPER, 1975a, p. 105.

Perspectivas - Revista do Programa de Pós-Graduação em Filosofia da UFT - v. 2 n. 2 (2017)
} 
Russell simplesmente não levou em consideração o importantíssimo fato de o argumento de Hume não mostrar a não-validade das inferências falsificadoras que vão da observação para a teoria. Ao contrário, medida pelos elevados padrões da crítica científica, a ciência nada mais é do que um sistema de conjecturas controladas pela crítica e pela experimentação. Nesse sentido, Popper afirma que não podemos dar nenhuma justificação positiva para nossas teorias e crenças, ou melhor, não é possível justificar as nossas teorias ou crenças racionalmente dando razões positivas, tais como o apelo à observação ou razões para considerá-las verdadeiras, mesmo que seja apenas de maneira provável (no sentido do cálculo de probabilidades $)^{18}$. Além disso, Popper afirma que:

\begin{abstract}
A crença segundo a qual podemos dar tais razões, e ainda segundo a qual deveríamos buscá-las, não é, ela mesma, uma crença racional nem verdadeira, mas sim uma crença que se pode mostrar ser sem préstimo.(...) supõe-se, sem crítica, que só uma perspectiva que carece de préstimo será destituída de base - sem base, no sentido de ser infundada, ou injustificada, ou sem apoio, ao passo que, segundo a minha perspectiva, todas as perspectivas - as boas e as más - são, neste importante sentido, destituídas de base, infundadas, injustificadas, sem apoio. (POPPER, 1987, p. 52-53)
\end{abstract}

Para ele, "todas as filosofias, até agora, foram justificacionistas" no sentido em que todas elas supuseram que a tarefa fundamental da teoria do conhecimento era mostrar que podemos justificar teorias ou crenças. Tanto os racionalistas e empiristas (neopositivistas) quanto os irracionalistas e céticos (humeanos) supõem que a questão da justificação ou da existência de razões positivas é fundamental para o conhecimento científico e tomam erroneamente a abordagem popperiana como uma forma de justificacionismo ${ }^{19}$. Nesse nível, afirmam os neopositivistas que o princípio do racionalismocrítico estaria sob as mesmas condições que o argumento racional positivo, já que também tal princípio tem sempre de se basear em algum pressuposto indemonstrável, de forma que a sua validade é relativa a esses pressupostos. Ou seja, sempre nos defrontamos com situações nas quais um argumento A é criticado em termos de um argumento B, este, por sua vez, é impossível de se estabelecer, de maneira que nenhuma crítica de A em relação a B será terminante. Segundo Popper, o erro da perspectiva do empirismo lógico consiste em não considerar que, nas nossas críticas, na maioria das vezes, trabalhamos com pressupostos indemonstráveis e injustificáveis; ou, por outras palavras, a nossa crítica nunca é, na verdade, terminante. De fato, a

\footnotetext{
${ }^{18}$ Cf. POPPER, 1987,p. 46.

${ }^{19}$ Cf. POPPER, 1987,p. 54.

Perspectivas - Revista do Programa de Pós-Graduação em Filosofia da UFT - v. 2 n. 2 (2017)
} 
indemonstrabilidade, seja de que gênero for, nunca ameaça a posição do racionalista crítico. Os seus argumentos, pautados no princípio do racionalismo crítico, assim como as teorias que critica em termos desses argumentos, são sempre conjecturais ${ }^{20}$. Essa distinção é expressa por Popper nos seguintes termos:

\begin{abstract}
A diferença é muito simples. O argumento justificacional, conducente a razões positivas, mais tarde ou mais cedo alcança razões que não podem, elas mesmas, ser justificadas (senão, o argumento levaria a um regresso infinito). E o justificacionista costuma tirar por conclusão que tais "pressupostos últimos" têm, de algum modo, de estar para além dos argumentos, não podendo ser criticados. Mas as críticas, as razões críticas oferecidas pela minha abordagem não são, em sentido nenhum, as últimas: também elas estão abertas à crítica; são conjecturais. Pode-se continuar indefinidamente a examiná-las; elas estão indefinidamente abertas ao reexame e à reconsideração. (POPPER, 1987, p. 60-61)
\end{abstract}

Com efeito, a crítica de Popper estabelece precisamente que só a exigência de prova ou de justificação é que origina um regresso infinito (ou mesmo um círculo vicioso) e também cria a necessidade de um termo último na discussão. O cerne da diferença entre a justificação buscada pelo positivismo lógico e o princípio do racionalismo crítico popperiano pauta-se no fato de que este último não gera nenhuma regressão ao infinito por que não está em causa provar nem justificar hipóteses, uma vez que não há necessidade de qualquer pressuposto supremo ${ }^{21}$.

Tendo demonstrado, do ponto de vista epistemológico, a inadequação da análise neopositivista da indução, Popper busca demonstrar, a partir de uma perspectiva lógica, a impossibilidade da indução em termos de uma lógica indutiva e de uma teoria indutiva probabilística. Assim, Popper busca interditar a possibilidade indutivista de realizar a união entre probabilidade e indução ${ }^{22}$.

As conclusões de Popper que emergem do exame das análises neopositivistas levadas a efeito no capítulo I estabelecem, categoricamente, que a probabilidade de hipóteses não pode ser reduzida à probabilidade de eventos ou de regularidades na natureza. E mais, ele não acredita que seja possível elaborar um conceito de probabilidade de hipóteses suscetível de ser interpretado como expressando o grau de validade ou confirmação de uma hipótese com relação aos conceitos verdadeiro e falso. Contudo, para resolver o problema da indução probabilística, adota a suposição de que tal conceito foi adequadamente elaborado a fim de

\footnotetext{
${ }^{20}$ Cf. POPPER, 1987,p. 60.

${ }^{21}$ Cf. POPPER, 1987, p. 61.

${ }^{22}$ Cf. POPPER,1975a, p. 290.

Perspectivas - Revista do Programa de Pós-Graduação em Filosofia da UFT - v. 2 n. 2 (2017)
} 
formular a questão: de que modo o conceito de indução probabilística afeta e auxilia o problema da indução? ${ }^{23}$.

Popper resume em três passos sua estratégia para levar a cabo a crítica ao indutivismo que busca apoio na probabilidade:

i) Primeiro, tomando a crítica de Hume da inexistência de uma justificação racional de um princípio de indução, concede espaço à possibilidade de existência da indução na ciência ${ }^{24}$.

ii) Segundo, assume que a indução pode ser conjugada com o cálculo de probabilidades, admitindo que faça sentido atribuir probabilidades a hipóteses;

iii) Por último, assume que a probabilidade de um enunciado universal pode ser diferente de zero.

O objetivo de Popper é criticar o mais severamente possível: a) a noção ou definição neopositivista de probabilidade; b) a possibilidade de uma lógica indutiva e de uma interpretação indutiva da probabilidade como suporte para uma indução probabilística. A partir disso, ele vai tentar mostrar que a indução probabilística, além de gerar equívocos, gera paradoxos ${ }^{25}$.

\section{CRÍTICA À PROBABILIDADE}

A interpretação lógica em termos de uma variante da interpretação subjetiva da teoria da probabilidade é, segundo Popper, sugerida pelo uso frequente de expressões de caráter fortemente psicológico, tais como confiança probabilística, expectativa matemática etc. As razões pelas quais Popper apresenta essa teoria como psicologista podem ser atestadas no fato de que ela trata o grau de probabilidade em termos de medida de sentimentos de certeza (ou incerteza), de crença (ou dúvida), despertados por certas afirmações ou conjecturas. Basicamente, a teoria subjetiva da probabilidade está apta a proporcionar uma solução para o problema de como apreciar os enunciados de probabilidade. Nesses termos, segundo Popper, a teoria psicologista pode ser mais bem percebida se considerarmos o fato de que os neopositivistas definem probabilidade como o grau de crença racional ou quantidade de confiança que é adequado conferir a um enunciado ${ }^{26}$.

\footnotetext{
${ }^{23}$ Cf. POPPER,1975a, p. 288.

${ }^{24}$ Cf. POPPER,1975a, p. 289.

${ }^{25}$ Cf. POPPER, 1987, p. 319.

${ }^{26}$ Cf. POPPER,1975a, p. 162-163.

Perspectivas - Revista do Programa de Pós-Graduação em Filosofia da UFT - v. 2 n. 2 (2017)
} 
A impotência da teoria subjetivista da probabilidade é partilhada por todas as epistemologias indutivistas, uma vez que questões subjetivistas sempre pedem respostas indutivistas. Nesse âmbito, Popper argumenta que há um fato que seduz e leva muitos filósofos da ciência a aceitar a indução probabilística, qual seja, o "fato indubitável” de que, segundo o cálculo de probabilidades, a probabilidade de uma proposição aumenta com a acumulação de evidências a seu favor, especialmente com acumulação de previsões bem sucedidas $^{27}$.

Assim, baseando-se no cálculo de probabilidades, Popper tenta mostrar que a probabilidade $\mathrm{p}(h, e)$ - de qualquer hipótese $h$ devendo tender para 1 com a acumulação de provas favoráveis $e$ - mesmo sendo grande, é totalmente ilusória. $\mathrm{O}$ argumento que ele combate tem a seguinte estrutura:

i) Seja $h$ uma hipótese cuja probabilidade inicial $\mathrm{p}(h)$ possa ser muito pequena, desde que diferente de zero;

ii) Seja $e$ qualquer prova (evidência) a seu favor;

iii) Assim, de $i$ e $i i$, temos $\mathrm{p}\left(h, e_{2}\right)>\mathrm{p}\left(h, e_{1}\right)$, se $e_{2}$ contiver uma prova favorável não ainda contida em $e_{1}$ (a conclusão a que se chega é que a probabilidade $\mathrm{p}(h)$ continua a aumentar com a acumulação das provas favoráveis $\left.e_{1}, e_{2}, e_{3}, \ldots, e_{\mathrm{n}}\right)^{28}$.

Segundo a análise popperiana, tudo pareceria completamente diferente se comparássemos duas ou mais hipóteses $\left(h_{1}, h_{2}, h_{3}, \ldots, h_{\mathrm{n}}\right)$ em competição e incompatíveis umas com as outras com uma prova $e$ constante favorável a todas elas. Tal comparação pretende mostrar que a influência exercida pelas provas sobre a probabilidade nada tem a ver com a indução. É o que ele pretende apontar a partir do seguinte argumento:

i) Sejam $h_{1}, h_{2}, h_{3}, \ldots, h_{\mathrm{n}}$ uma sequência de hipóteses em competição e incompatíveis umas com as outras;

ii) Seja $e$ o conjunto das provas relevantes (ou as previsões bem sucedidas) deriváveis de cada uma das $n$ hipóteses do conjunto, de modo que tenhamos $\mathrm{p}\left(h_{1}, e\right)>\mathrm{p}\left(h_{1}\right)$ e $0<\mathrm{p}(e)$ $<$ 1. Obtemos imediatamente, do teorema geral da multiplicação do cálculo de probabilidades ${ }^{29}$ o teorema $\mathrm{p}\left(h_{1}, e\right)>\mathrm{p}\left(h_{1}\right)$, que diz que as provas favoráveis $e$ aumentam a probabilidade da hipótese $h_{1}$;

\footnotetext{
${ }^{27}$ Cf. POPPER, 1987, p. 342.

${ }^{28}$ Cf. POPPER, 1987, p. 342-346.

${ }^{29}$ Cf. POPPER,1975a, p. 317.

Perspectivas - Revista do Programa de Pós-Graduação em Filosofia da UFT - v. 2 n. 2 (2017)
} 
iii) Entretanto, também obtemos o teorema $\mathrm{p}\left(h_{1}, e\right)<\mathrm{p}\left(h_{2}, e\right)$ se e somente se $\mathrm{p}\left(h_{1}\right)<$ $\mathrm{p}\left(h_{2}\right)$, que mostra que as provas favoráveis $e$, apesar de aumentarem a probabilidade de $h_{1}$, contrariam o primeiro teorema, deixando tudo precisamente como estava, não podendo favorecer nem $h_{1}$ e nem $h_{2}$ (ao contrário, o segundo teorema mantém a ordem inicial conferida às hipóteses no conjunto dado antes das provas; tal ordem é inabalável por quaisquer provas favoráveis, não podendo ser influenciada por estas) $)^{30}$.

A conclusão a que se chega a partir de iii é que $h_{1}$ pode ser uma generalização indutiva típica das provas $e$, enquanto $h_{2}$ pode fazer afirmações que não têm apoio nenhum de $e$, de modo que $h_{2}$ está muito longe de ser uma generalização de $e$, o mesmo sendo notado se assumirmos uma posição contrária. De modo a tornar o assunto mais claro, Popper se vale do seguinte exemplo. Consideremos que:

i) $e$ registra que um milhão de cisnes observados são brancos e que também foram encontrados cisnes que não são brancos;

ii) $h_{1}$ diz "Todos os cisnes são brancos";

iii) $h_{2}$ diz "Os cisnes na Itália, na Grécia e na França são brancos; na Inglaterra e na Escandinávia, são vermelhos; na Ásia central, são verdes; na África, são azuis; e na Austrália, são pretos";

iv) $b$ representa certo conhecimento de fundo segundo o qual não foram observados cisnes fora da Grécia, da Itália e da França ${ }^{31}$.

Aplicando, agora, $h_{1}$ a todo o Universo, podemos tornar sua probabilidade inicialmente igual ou mesmo menor que a de $h_{2}$. Ou ainda enfraquecer $h_{2}$ para a tornarmos mais provável, supondo que $\mathrm{p}\left(h_{1}\right) \leq \mathrm{p}\left(h_{2}\right)$ e que $\mathrm{p}\left(h_{1}, b\right) \leq \mathrm{p}\left(h_{2}, b\right)$. Uma vez que $e$ registra casos de cisnes brancos observados e casos de cisnes não-brancos observados, e $b$ afirma que não foram observados cisnes fora da Grácia, Itália e França (portanto, não foram observados cisnes não-brancos), teremos $\mathrm{p}\left(h_{1}, e b\right)<\mathrm{p}\left(h_{2}, e b\right)$ se e somente se $\mathrm{p}\left(h_{1}, b\right)<\mathrm{p}\left(h_{2}, b\right)$. Assim, fica demonstrado que $e$ não apoia a generalização direta de $h_{1}$ mais do que apoia a hipótese $h_{2}$. De acordo com Popper, isso mostra que o argumento de que a probabilidade de uma proposição aumenta com a acumulação de evidências a seu favor (especialmente com acumulação de previsões bem sucedidas) é erroneamente interpretado, quando tomado como

\footnotetext{
${ }^{30} \mathrm{Cf}$. POPPER, 1987, p. 346.

${ }^{31}$ Cf. POPPER, 1987, p. 344.

Perspectivas - Revista do Programa de Pós-Graduação em Filosofia da UFT - v. 2 n. 2 (2017)
} 
apoiando a indução ou a generalização indutiva. E mostra, também, que o cálculo de probabilidades não tem utilidade nenhuma como uma teoria da indução ${ }^{32}$.

Esta consideração torna perfeitamente claro que nunca obteremos uma alta probabilidade para qualquer hipótese, apesar de quaisquer provas de apoio. A questão advogada aqui é a de que racionalmente não podemos nunca atribuir uma alta probabilidade a qualquer hipótese, ainda que para ela sejam dadas as mais excelentes provas. Nesses termos, a probabilidade (no sentido do cálculo de probabilidades) não pode ser um bom instrumento para explicar o fato de uma hipótese ser sempre bem-sucedida em fazer previsões não esperadas. A ideia contrária pode ter decorrido do fato de que a probabilidade de uma proposição aumenta com a acumulação de provas a seu favor, especialmente com acumulação de previsões bem-sucedidas. Do que se disse até aqui, deve ficar claro que, se a alta probabilidade é um dos objetivos da ciência, isso é paradoxal. O propósito dos cientistas é fazer com que a ciência "progrida", quer dizer, é acrescentar cada vez mais ao seu conteúdo, o que significa reduzir sua probabilidade. Tendo em vista a extensão das leis científicas, não é surpreendente que sua probabilidade seja zero, nem que as filosofias que acreditam que a ciência precisa ter por objetivo probabilidades elevadas não possam reconhecer que o seu objetivo mais importante é a formulação de leis universais ${ }^{33}$.

Popper está interessado em enunciados que encerrem alto conteúdo informativo, consistindo esse conteúdo de todas as proposições não tautológicas suscetíveis de serem dele deduzidas. Contudo, quanto maior o conteúdo informativo, menor a probabilidade, pois quanto mais informação um enunciado contenha, maior o número de maneiras segundo as quais ele poderá mostrar-se falso. O que se deseja são enunciados de alto conteúdo informativo e, consequentemente, de baixa probabilidade, os quais, não obstante, se aproximem da verdade. $\mathrm{O}$ fato de esses enunciados serem altamente falseáveis torna-os, também, altamente suscetíveis de serem submetidos a teste: o conteúdo informativo que está em proporção inversa à probabilidade, está em proporção direta à possibilidade de testes. $\mathrm{O}$ enunciado verdadeiro com o mais alto conteúdo informativo possível corresponderia à completa e precisa descrição do mundo; e toda observação ou experiência possível constituiria, para essa descrição, um teste (ou uma potencial falsificação) ${ }^{34}$.

\footnotetext{
${ }^{32}$ Cf. POPPER, 1987, 344-346.

${ }^{33}$ Cf. POPPER, 1982, p. 314-315.

${ }^{34}$ Cf. POPPER,1982, p. 314-316.
}

Perspectivas - Revista do Programa de Pós-Graduação em Filosofia da UFT - v. 2 n. 2 (2017) 
Após ter apresentado a sua crítica à indução e à solução neopositivista para tal problema, Popper intenta criticar a perspectiva empirista relativa ao problema da demarcação entre ciência e metafísica. A verdade é que, desde a sua primeira publicação sobre o assunto, ele rejeita o problema da falta de significado dos enunciados da metafísica como pseudoproblema, além de não o identificar com o problema da demarcação. Nesse sentido, as críticas mais importantes do filósofo ao critério empirista de demarcação buscam atingir um problema ainda maior, qual seja: o da justificação dos métodos indutivos na ciência.

\section{CONSIDERAÇÕES FINAIS}

Em seu livro Conjecturas e refutações Popper apresenta o problema da demarcação como sendo

(...) o problema de como traçar uma linha fronteiriça entre afirmativas e sistemas de afirmativas que podem ser qualificados propriamente como pertencentes à ciência empírica e outros que talvez possam ser descritos como pseudocientíficos ou, em determinados contextos como metafísicos; ou ainda que pertençam possivelmente ao campo da lógica e da matemática puras. (POPPER,1982, p. 283)

Por não aceitar a explicação de que a ciência se caracteriza na sua base pela observação e pelo método indutivo, enquanto a pseudociência e a metafísica se caracterizariam pelo método especulativo ou pelo fato de funcionar como antecipações mentais.

Para Popper, o problema da demarcação não é apenas o de classificar teorias em científicas e não-científicas. Antes disso, ele decorre da necessidade urgente de se fazer uma apreciação crítica das teorias científicas ou pretensamente científicas. No que toca à ciência e à metafísica, Popper não concebe de maneira alguma algo como uma demarcação clara ${ }^{35}$. Para ele, a ciência foi sempre, em todas as épocas, profundamente influenciada por ideias metafísicas. Destarte, não pode haver uma demarcação clara entre ambas ${ }^{36}$. Acerca dessa consideração, diz ele:

\footnotetext{
${ }^{35} \mathrm{O}$ problema central de Popper é o de caracterizar a ciência empírica e não demarcá-la com referência à metafísica. Sua intenção é mostrar que pode existir empiricidade sem indução. Na medida em que a perspectiva popperiana de ciência valoriza fortemente a especulação, não se procura uma demarcação entre o empírico e o especulativo - esta distinção pertence à corrente neopositivista. Assim, no sistema popperiano, podemos, simultaneamente, ter uma caracterização de ciência que seja tanto empírica quanto especulativa - enquanto a metafísica é tão somente especulativa. Consequentemente, a demarcação entre ciência e metafísica torna-se algo trivial no pensamento popperiano (Cf. POPPER, 1975a, p. 34-35ss).

${ }^{36}$ Cf. POPPER, 1987, p. 177.
}

Perspectivas - Revista do Programa de Pós-Graduação em Filosofia da UFT - v. 2 n. 2 (2017) 


\begin{abstract}
Não creio que a metafísica seja algo sem-sentido, e não acho que seja possível eliminar todos os "elementos metafísicos" da ciência: eles estão intimamente entrelaçados com os restantes. No entanto, julgo que sempre que seja possível encontrar-se em ciência um elemento metafísico que possa ser eliminado, a eliminação será benéfica. Pois a eliminação de um elemento não testável da ciência remove um meio de se evitarem refutações; e isto terá tendência para aumentarem a testabilidade ou a refutabilidade da teoria em causa. E, na verdade, houve um certo número de casos de teorias científicas que ganharam muito com a descoberta de que havia nelas elementos metafísicos que podiam ser eliminados, e com a tentativa de os eliminar. (POPPER, 1987, p. 195)
\end{abstract}

Na perspectiva popperiana, o problema da demarcação está intimamente relacionado ao problema de decidir entre teorias em competição. Tal problema envolve decidir se é possível ou não justificar racionalmente uma teoria, ou seja, distinguir entre uma teoria racional e uma crença irracional. Isto é frequentemente identificado com o problema de demarcar teorias empíricas (ou científicas) com respeito a teorias metafísicas (ou nãoempíricas) ${ }^{37}$.

Segundo a metodologia de Popper, o método neopositivista da verificação é acrítico, pois constitui um erro fundamental acreditar que - por ser constantemente verificada a partir da experiência - uma teoria tem de ser obrigatoriamente científica. Além disso, a verificação menospreza o fato de a discussão científica ser uma discussão crítica e também não leva em consideração o importantíssimo fato de a atitude fundamental do cientista ser a de procurar refutações, e não verificações ${ }^{38}$.

Contudo, a crítica de Popper ao critério de verificação busca demonstrar que as teorias científicas não podem ser reduzidas a observações, uma vez que isto as leva a terem o mesmo status das teorias metafísicas ${ }^{39}$.

Popper rejeita o dogma de que as proposições metafísicas têm de ser excluídas da classe das afirmativas com sentido, simplesmente porque, à luz de considerações da história da ciência, algumas teorias, como o atomismo e a teoria corpuscular da luz revelaram-se, durante muito tempo, não testáveis e, nessa medida, foram consideradas "metafísicas". Mesmo assim, mais tarde, elas passaram a fazer parte da física ${ }^{40}$.

Para Popper, dentro da classe de todas as afirmativas de uma linguagem, as da ciência constituem a parte testável, ao passo que as da metafísica constituem a não-testável ${ }^{41}$.

\footnotetext{
${ }^{37}$ Cf. POPPER, 1987, p. 179.

${ }^{38} \mathrm{Cf}$. POPPER, 1987, p. 180-181.

${ }^{39}$ Cf. POPPER, 1975a, p. 38; 1982, p. 223-226.

${ }^{40} \mathrm{Cf}$. POPPER, 1982, p. 285.

${ }^{41}$ Cf. POPPER, 1982, p. 284.

Perspectivas - Revista do Programa de Pós-Graduação em Filosofia da UFT - v. 2 n. 2 (2017)
} 
A intenção de Popper, ao traçar essa distinção, é mostrar que a concepção verificacionista desenvolvida pela corrente neopositivista é equívoca, pois, se as leis da ciência são conseguidas através da indução, então devemos sempre procurar casos singulares que verifiquem a lei, o que forçosamente nos leva à verificação de todo o universo possível de tais casos. Em outras palavras, por esse método, torna-se necessário que todos os casos instanciaisda hipótese sejam conformes à lei. Em termos de probabilidade, isso implica na aceitação da existência de probabilidades iguais a 1, o que é impossível. Para Popper fica claro que a probabilidade $\mathrm{p}(h)=1$ de uma lei é inaceitável, não só do seu ponto de vista como também da perspectiva de seus oponentes indutivistas, que, indiscutivelmente, não podem aceitar como consequência o fato de a probabilidade de uma lei universal jamais se ver aumentada pela experiência. Com efeito, "todos o cisnes são brancos" teria a probabilidade 1, tanto quanto "todos os cisnes são pretos" (e o mesmo para quaisquer outras cores). Por outro lado, dada a extensão das leis científicas, qualquer instanciação delas através de enunciados singulares implicará em probabilidades iguais a zero (assim, "existe um cisne branco", "existe um cisne preto", etc. teriam todos a probabilidade zero), simplesmente porque a definição clássica de probabilidade da hipótese a dá como o número de possibilidades favoráveis dividido pelo número de todas as possibilidades, ou melhor, como o quociente entre o número de casos verificados, que é finito, e o número de casos não-verificados, que é infinito ${ }^{42}$.

Ao negar que haja realmente procedimento de verificação, porque todos os testes a que são submetidas as teorias não passam de tentativas de refutação, Popper mostra, finalmente, que uma teoria considerada verificada pela experiência não passa de uma teoria que ainda não foi infirmada, apesar dos esforços para consegui-lo. O princípio de verificação determina que só seriam dotados de sentido os enunciados empíricos capazes, pelo menos em princípio, de serem verificados completamente por uma evidência de tipo observacional. Ora, de acordo com a análise crítica popperiana, semelhante posição não somente é fatal para a metafísica, mas para a própria ciência, uma vez que todas as proposições estritamente universais, quer dizer, aquelas que exprimem as leis científicas, são proposições que não podem ser verificadas por nenhum conjunto finito de enunciados observacionais ${ }^{43}$.

A concepção crítica de Popper, ao apontar a inadequação do critério empirista para a demarcação entre ciência e metafísica, consiste, antes de qualquer coisa, na tese de que os

\footnotetext{
${ }^{42}$ Cf. POPPER, 1975a, p. 417.

${ }^{43}$ Cf. POPPER, 1982, p. 309-310.

Perspectivas - Revista do Programa de Pós-Graduação em Filosofia da UFT - v. 2 n. 2 (2017)
} 
métodos empiristas para verificar uma proposição têm por fundamento, essencialmente, o método indutivo. Se, ao invés de procurar eliminar a metafísica tentasse os neopositivistas eliminarem a indução por recurso à abordagem crítica, a consequência desta atitude seria uma melhor análise da ciência empírica. De resto, pode-se dizer que, na ótica positivista, uma expressão linguística só pertencerá ao campo das ciências empíricas se for logicamente possível verificá-la pelos métodos indutivos ou pela evidência indutiva ${ }^{44}$.

A crítica popperiana contra os que defendem tais critérios consiste no simples fato de que eles não excluem proposições que são obviamente metafísicas; excluem, porém, as afirmações científicas mais importantes e interessantes - isto é, as teorias científicas ou as leis universais da natureza. De um ponto de vista lógico, Popper procura criticar o problema da exclusão das leis científicas demonstrando que a verificação, como critério de demarcação, não possui nenhum caráter seletivo capaz distinguir teorias científicas e não científicas $^{45}$.

A posição de Popper frente à eliminação da indução, a partir do princípio do racionalismo crítico, indica-nos que o procedimento que se adota para a justificação racional de hipóteses pode ser explicado sem o uso da lógica indutiva. Do mesmo modo, ao demonstrar a inadequação do critério empirista, busca demonstrar a ineficácia dos métodos indutivos como critério de demarcação, uma vez que a indução subjaz a tais critérios. Nesses termos, uma teoria da indução torna-se supérflua, não tendo nenhum papel a desempenhar em uma lógica da ciência.

\section{REFERÊNCIAS}

HUME, David. (1996) Investigação acerca do entendimento humano (Col. "Os Pensadores"). Trad. Anoar Aiex. São Paulo: Nova Cultural, 1996.

(2001) Tratado da natureza humana: uma tentativa de introduzir o método experimental de raciocínio nos assuntos morais. Trad. Déborah Danowski. São Paulo: Editora UNESP, 2001.

KLIMOVSKY, Gregorio. (1995) Las desventuras del conocimiento científico. Buenos Aires: A-Z editora, 1995.

POPPER, Karl Raimund.(1975a) A lógica da pesquisa cientíica. Trad. Leonidas Hegenberg e Octanny Silveira da Mota. São Paulo: Cultrix, 1975.

\footnotetext{
${ }^{44}$ Cf. POPPER, 1982, p. 308.

${ }^{45}$ Cf. POPPER, 1982, p. 309.

Perspectivas - Revista do Programa de Pós-Graduação em Filosofia da UFT - v. 2 n. 2 (2017)
} 
(1975b) Conhecimento objetivo: uma abordagem evolucionária. Trad. Milton Amado. Belo Horizonte: Itatiaia/Edusp, 1975.

- (1982) Conjecturas e refutações. Trad. Sérgio Bath. 2a ed. Brasília: Editora Universidade de Brasília, 1982.

(1987) O realismo e o objetivo da ciência (Pós-escrito à Lógica da pesquisa científica, vol.1). Trad. Nuno Ferreira da Fonseca. Lisboa: Dom Quixote, 1987. 